\title{
Recurrent pain-abdomen, breathlessness and abdominal injury in the remote past
}

\author{
Vipin Kumar Jain, ${ }^{1}$ Rajendra Takhar, ${ }^{1}$ Mustufa Malik, ${ }^{2}$ Rakesh Biswas ${ }^{2}$
}

${ }^{1}$ Department of Pulmonary Medicine, Bhopal, Madhya Pradesh, India ${ }^{2}$ Department of General Medicine, Peoples College of Medical Sciences and Research Centre, Bhopal, Madhya Pradesh, India

\section{Correspondence to} Professor Rakesh Biswas, rakesh7biswas@gmail.com

\section{CrossMark}

To cite: Jain VK, Takhar $\mathrm{R}$ Malik $M$, et al. BMJ Case Rep Published online: [please include Day Month Yearl doi:10.1136/bcr-2013202916

\section{DESCRIPTION}

A 27-year-old man presented with a history of abdominal pain, vomiting and occasional dry cough associated with breathlessness which was worsening on lying down but not relieved by sitting. He had recurrent episodes of similar illness since the past 5 months, and for that he took symptomatic treatment and got relief to some extent. There was no history of wheezing, fever, chest pain, loss of weight or appetite. The patient had a significant history of blunt trauma to the thorax and abdomen 3 years ago by a Pokland machine (a machine used for agriculture purposes), which resulted in bilateral rib fracture that was managed efficiently at that time.

Physical examination, vitals and laboratory investigations revealed no abnormality except for decreased breath sound throughout the left side of the chest. Chest X-ray revealed raised hemidiaphragm and air fluid level on the left side (figure 1). Thoracoabdominal CT showed a breach in the left hemidiaphragm (posterior part) along with herniated abdominal contents in the left pleural cavity and left lung with mediastinum found shifted towards the right (figure 2), confirming the diagnosis of post-traumatic diaphragmatic hernia. On exploratory laparotomy, a diaphragmatic defect of $10 \times 10 \mathrm{~cm}$ in size with the whole of the stomach, transverse colon and a part of the small bowel found herniated in the left hemithorax. Along with laparotomy, the patient underwent simultaneous left thoracotomy and operative repair included reduction of the incarcerated contents after assessing their viability, drainage of the pleura and closure of the diaphragmatic defect by mesh hernioplasty. Postoperatively the patient was alright and a repeat chest X-ray was absolutely normal

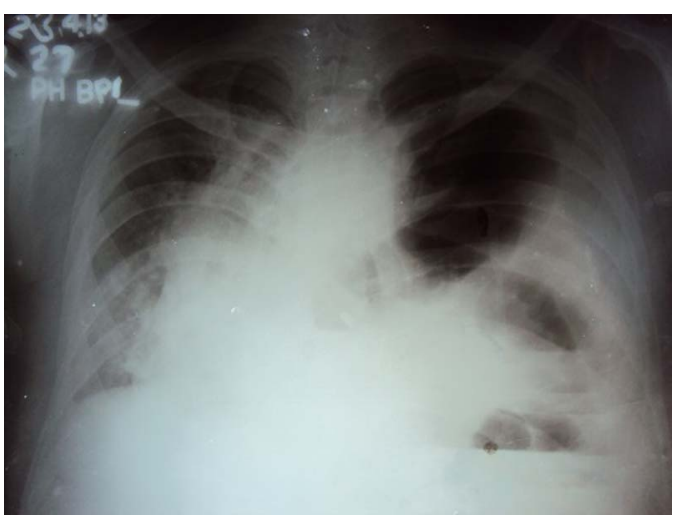

Figure 1 Chest X-ray posterioranterior view: indistinct hemidiaphragm and air fluid levels on the left side.

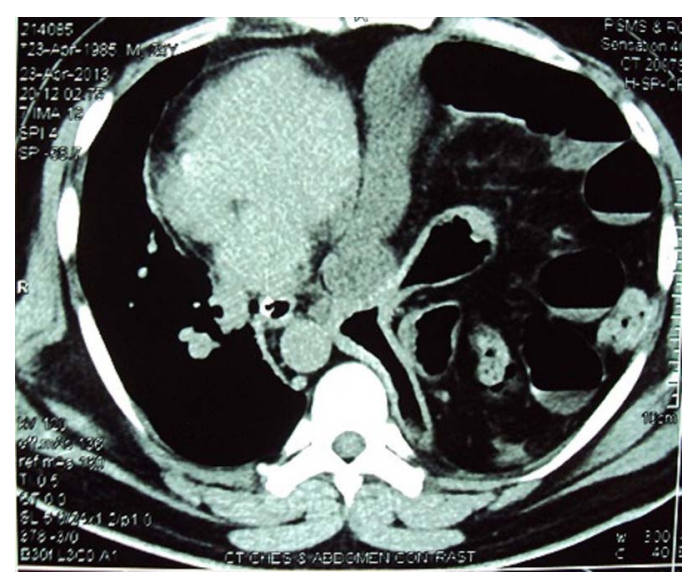

Figure 2 Breach in left hemidiaphragm with herniated abdominal contents in the left pleural cavity and mediastinal shifting towards the right.

showing a clear left diaphragmatic border and no residual air fluid level.

Diaphragmatic rupture is a life-threatening complication of thoracoabdominal trauma. The condition may present spontaneously or passed unnoticed, to present many years afterwards. A delayed traumatic diaphragmatic hernia is a rare diagnosis and intrathoracic herniation of abdominal organs is a great diagnostic difficulty as it often presents with vague unrelated clinical symptoms ${ }^{1}(\mathrm{eg}$, pain abdomen, breathlessness, vomiting) and nonspecific radiographic findings long after the initiating trauma has been forgotten. There may be a delay between trauma and diagnosis ranging from $24 \mathrm{~h}$ to 50 years. $^{2}$ A number of factors cause delayed diagnosis including serious concurrent injuries and a paucity of pathognomonic clinical signs and simultaneous lung injuries which may mask or mimic the diagnosis. Another likely explanation for delay in diagnosis is that the diaphragmatic defect occurring with injury manifests only when the progressive visceral herniation occurs through this defect from the constant negative intrapleural pressure pulling on mobile abdominal viscera. ${ }^{3}$

The radiological work-up consists of chest X-ray and CT scans of the chest and abdomen. ${ }^{2}$ On the chest radiograph, diagnostic criteria suggestive of a ruptured diaphragm are the presence of bowel loops in the chest, unclear diaphragmatic outline and a markedly elevated hemidiaphragm. ${ }^{1}{ }^{2}$

A prompt diagnosis and an operative intervention form the cornerstone of the management for the post-traumatic diaphragmatic hernias. Thoracotomy (if required, extended into a thoracoabdominal incision) is advised in the patients with delayed 
presentation since the adhesions within the chest can be freed easily, and reduction and repair of hernia will be easily accomplished. The principles of an operative repair include reducing the incarcerated contents, removal of the hernia sac, drainage of the pleura and closure of the diaphragmatic defect. ${ }^{2}$

\section{Learning points}

- Post-traumatic sequelae-like diaphragmatic hernia is not uncommon and must be considered, especially in blunt abdominal trauma, and they can present even years after a traumatic event.

- Diagnosis of this entity is notoriously difficult as these patients present many a times with non-specific symptoms, but failure to make this diagnosis carries a high mortality rate. A high index of suspicion must be maintained.
Acknowledgements The authors acknowledge the Department of Cardiothorasic Surgery, Bhopal Memorial Hospital and Research Centre for looking after the surgical part of the treatment.

Contributors VKJ was the main author of the article while RT and RB were involved in conducting all the relevant investigation, treatment of the patient, collection of data and reviewing the script in the final stage. MM collected consent, relevant references and critical review of the paper in the final stage.

Competing interests None.

Patient consent Obtained.

Provenance and peer review Not commissioned; externally peer reviewed.

\section{REFERENCES}

1 Rashid F, Chakrabarty MM, Singh $R$, et al. A review on delayed presentation of diaphragmatic rupture. W J Emerg Surg 2009;4:32.

2 Demuro JP. A delayed traumatic diaphragmatic hernia presenting with a bowel obstruction 20 years post-injury. J Clin Diagn Res 2013;7:736-8.

3 Meyers BF, McCabe CJ. Traumatic diaphragmatic hernia. Occult marker of severe injury. Ann Surg 1993;218:783

Copyright 2014 BMJ Publishing Group. All rights reserved. For permission to reuse any of this content visit http://group.bmj.com/group/rights-licensing/permissions.

BMJ Case Report Fellows may re-use this article for personal use and teaching without any further permission.

Become a Fellow of BMJ Case Reports today and you can:

- Submit as many cases as you like

- Enjoy fast sympathetic peer review and rapid publication of accepted articles

- Access all the published articles

- Re-use any of the published material for personal use and teaching without further permission

For information on Institutional Fellowships contact consortiasales@bmjgroup.com

Visit casereports.bmj.com for more articles like this and to become a Fellow 